\title{
Discussions on Strengthening the Practical Engineering Capabilities of Chemical Engineering Instructors
}

\author{
Yu'e Qiu (Corresponding author) \\ Department of Chemistry, Dezhou University \\ Dezhou 253023, China
}

Tel: 86-534-898-7866_E-mail: zyzh200311@yahoo.com

\author{
Xiuling Zhang \\ Department of Chemistry, Dezhou University \\ Dezhou 253023, China \\ E-mail: xlzhang99@126.com
}

$\begin{array}{lc}\text { Received: November 29, } 2011 & \text { Accepted: January 2, } 2012 \quad \text { Published: March 1, } 2012 \\ \text { doi:10.5539/ass.v8n3p338 } & \text { URL: http://dx.doi.org/10.5539/ass.v8n3p338 }\end{array}$

The research is funded by Shandong Education Science 'ten-one-five’ planning projects (2008GG112 and 2010GZ081).

\begin{abstract}
The authors propose a series of methods and approaches, including working at the first-line of chemical engineering production, recruiting industry experts to give lectures on topics of chemical engineering, and optimizing the annual evaluation systems and policy guidance to entitle and rank professional titles, in order to strengthen practical engineering capabilities of chemical engineering instructors and to educate high-level application type talents in the field of chemical engineering.
\end{abstract}

Keywords: Chemical engineering enterprise, Chemical engineering instructors, Practical engineering capability

\section{Introduction}

The 21 st century is a knowledge-based economy. The science and technology advancement is an important factor to weigh a country's competitive strength. The future society is in need of creative talents, and has an even stronger demand for high-level application type talents with strong practical engineering capabilities. The chemical engineering higher education should suit to the society's demand, and truly achieve the seamless transition of school education and employment companies, students' capabilities and job requirements, to help graduates easily find a job to serve the society. Therefore targeting on the common situation of relatively weak practical engineering capabilities of chemical engineering instructors, the authors have proposed the following methods or approaches, including working at the first-line of chemical engineering production, recruiting industry experts to give lectures on topics of chemical engineering, and optimizing the annual evaluation systems and policy guidance to entitle and rank professional titles, in order to strengthen practical engineering capabilities of chemical engineering instructors and to educate high-level application type talents in the field of chemical engineering.

\section{Current Situations of the Practical Engineering Capabilities of Chemical Engineering Instructors and the Causal Analysis}

Currently, among the engineering universities and colleges in China, especially the newly merged regional universities, it is common that the universities emphasis on theory and neglect practice in chemical engineering teaching. The practical education is not given enough attention and the goal of practical education has not been thoroughly and effectively fulfilled. Thus the results of higher education on chemical engineering are not quite satisfactory, which directly weakens the education of chemical engineering application type talents. In fact, all 
the above facts are due to the relative weak practical engineering capabilities of chemical engineering instructors. Therefore, it is necessary and important to conduct the causal analysis and seek the solutions to strengthen the practical engineering capabilities of chemical engineering instructors.

\subsection{The Existing Chemical Engineering Instructors Have Relatively Weaker Practical Engineering Capabilities}

As an important component of engineering education, chemical engineering education is very practical and has a lot of applications. However, due to the recent sharp education enrollment increase in relative short times in China, there is a severe shortage of chemical engineering instructors. In order to raise the teacher-student percentage, many universities recruit a high volume of recent graduates, especially post-graduates from key universities. Most of the new recruits have Ph.D. or M.S. degrees with higher education levels, better comprehensive qualities and research abilities, and they have injected energies into the instructors' team and contribute to the promotion of the research levels. However, most of those young instructors have stayed at school all the time, directly from students to teachers. And they rarely have experiences in the real practice of chemical industry and the first line production, thus their theory and practical engineering capability are usually not connected, and they can hardly perform teaching activities which relates the theory to the real engineering problems. For example, from 2008 to 2010, there are 33 instructors in the field of chemical engineering in Dezhou University, 30 of them are under 45 , which is $90.91 \%$ of the entire teacher population, and 26 are under 35 , which accounts $78.79 \%$. And 27 of them have Ph.D. and M.S. degrees, which is $81.82 \%$. Middle-aged and young instructors are majority and most of them have never had specialized and long-team chemical engineering trainings and practical experiences, and they also lack industry background and engineering capabilities. Therefore during their teaching process, they can only refer to the content from textbooks, and cannot explain fundamental theories and technics using practical engineering examples and enrich their class content with real problem occurring during the chemical engineering production process. Thus the students' engineering capabilities have been affectedly greatly and they need a relatively longer adjustment period after they find a job in real world. Similar instructor compositions exist in a lot of other universities, for example, Shandong Science and Technology University, Shandong Polytechnic University, Weifang University, and Binzhou University.

\subsection{The causal analysis of why current chemical engineering instructors have relatively weaker practical engineering capabilities}

In summary, there could be several reasons for this phenomenon as follows. First, the traditional engineering education philosophy and teaching mode have negative impacts on the practical engineering capabilities of chemical engineering instructors. For a long time, restricted by the traditional education mode, the engineering higher education in China basically follow the education mode of emphasizing theory and neglecting practice, and the instructors neglect the practical teaching process and the education of students' practical capability, innovation and knowledge integration capability, which are extremely important in engineering education. Due to this specialized or restricted cramming method of teaching, students are suffering from disconnection of theories and practice. It also has a huge negative effect on the engineering instructors' thought, quality, and teaching abilities on practical education.

The second reason is about the impact of the highly dangerous characteristics of chemical engineering industry on the practical engineering abilities of instructors. In the chemical engineering industry, most of the production processes involve high temperature, high pressure, explosive and combustible conditions, so the industry has become the third highly dangerous industry behind the mining and fireworks industry. In addition, after entering into market economy, the existence and development of chemical engineering enterprises are rooted in economic profits and most enterprises are considering students' interns as an extra burden, as the students will not create economic profits for the enterprise and may even disturb normal production orders, and bring potential hazardous factors to safety in production. Even some enterprises agree to accept students, they only allow students to visit and look around instead of practicing by themselves and having real job responsibilities. So the practical training or internships of chemical engineering students is restricted to the surface, and cannot go deeper into the real chemical engineering production process due to the special characteristics of chemical industry. It's easy to imagine the low level practical engineering capabilities of the inexperienced instructors directly graduated from universities.

The third reason is due to the lack of evaluation systems of promotion on the practical engineering abilities of engineering instructors. Research of science and technology is the internal drive for university development and the key factor to strengthen a university's intrinsic value. So for a long time, during the annual evaluation and professional title promotion, research findings and published papers are highly valued. There are no evaluations for their practical teaching activities and the improvement of manipulative ability corresponding to the 
characteristics of engineering instructors. Therefore, the engineering instructors have lost crisis awareness, pressure and motivation for improving their own practical engineering capabilities.

\section{The Methods and Approaches to Promote the Practical Engineering Capabilities of Chemical Engineering Instructors}

To improve the practical engineering capabilities of chemical engineering instructors as soon as possible is an urgent requirement of the chemical engineering higher education reform and educating high-level application type chemical engineering talents. Based on the authors' long time teaching experiences and the feedbacks from the industry, we propose the following methods and approaches.

3.1 Working at the production first-line of chemical engineering and improving practical teaching capabilities for chemical engineering instructors

The best way for chemical engineering instructors to gain thorough and systematic engineering practical knowledge is to go deep into the production first-line in enterprises. There are two approaches according to the occupational characteristics of instructors. The first is to work as an intern in chemical engineering enterprise during summer or winter vacations. Instructors are quite busy with teaching and researching during semesters, and they don't have extra time to participate in the practical production activities. They can only spare some time during the summer or winter vacations to work at the production first-line in chemical engineering enterprises as unpaid interns, involve in the technical engineering occupations and help the enterprise to solve technical difficulties. These activities can make up for the deficiency of technical force in small or medium-sized enterprises, and also strengthen the practical engineering capabilities of the instructors. The second approach is that the specialized instructors collaborate with the technicians from chemical engineering enterprises on technical research or major technical reformation projects. The chemical engineering instructors possess solid professional theoretical knowledge, and the technicians have rich engineering practical experiences. Therefore, the collaboration of the two on technical research or major technical reformation engineering projects will trigger the economy development in the region that the university serves, as well as strengthen the instructors' practical engineering capabilities.

3.2 Recruiting industrial experts to give lectures on topics of chemical engineering and improving instructors' practical teaching capabilities

Currently a plenty of application types universities have hired industry technicians to participate in the teaching process to educate high quality application type engineering talents. It has overcome the instructors' disconnections between engineering theory and practical engineering capabilities, but it also increased the cost of education. What we have done is that we invite some successful entrepreneurs, start-up business owners, technicians and advanced engineers working at the front-line production with abundant practical engineering experience from chemical engineering enterprises to give lectures on topics of chemical engineering, and explain the cutting edge development in the industry and the latest chemical engineering products and technology for instructors and students. This could not only wide the knowledge and visions of the instructors and students, but also strengthen the linkage between the universities and enterprises. Based on this, we have founded some practical teaching bases outside the campus selectively according to the needs of practical teaching. With the foundation of these practical teaching bases, we can provide various practices or intern opportunities for the students, and also make it convenient for engineering training of specialized instructors in the engineering practices frontline.

3.3 Optimizing the annual evaluation systems and policy guidance to entitle and rank professional titles of instructors and motivating instructors to attend practical teaching activities

In order to encourage the specialized instructors in chemical engineering to participate into practical teaching activities and improve their capabilities in practical teaching, we should optimize the regulation, incentive and evaluation mechanisms in the annual evaluation system and policy guidance of ranking and awarding professional titles for instructors. The capability and working performance of resolving practical engineering problems should be included as an evaluation factor into the professional titles evaluation. Corresponding academic and technical positions should be entitled to instructors contributing to solving major engineering technical problems.

\section{Conclusions}

Improving the practical engineering capabilities of specialized instructors in chemical engineering is not only the basic requirement of chemical engineering higher education, but also the requirement of chemical engineering industry's need for application type engineering talents. It is also the requirement for schools to obey the major 
education goals. The universities should take every effective action to improve the practical engineering capabilities of specialized instructors in chemical engineering, especially those young and middle-aged instructors, in order to raise the quality of chemical engineering education.

\section{References}

Education Bureau of the City of Liaoyuan. (2002). Implementation of 'Research-Promoted Education' Strategy to Promote Comprehensive Development of Education Reform. Modern education technology, 2, 30-33.

Xiao, L. (2010). Handling the Accident Scene of Dangerous Chemicals. The modern job safety, 2, 63.

Yu, G. \& Huang, J. (2006). Employing Industry Teachers' effect to educate application type engineering undergraduates. Journal of Hunan Institute of Engineering, 16(2), 76-78.

Zhang, Y. (1999). Opinions on Teachers' Practical Engineering Capacities in Regional Colleges of Engineering. Journal of Chongqing Institute of Technology Management, 13(6), 48-50.

Zheng, S. \& Song, W. (2009). Research on the Chinese Chemical Engineering Enterprises' Society Responsibilities System. The world of entrepreneurs (theory edition), 12, 45-46. 